\title{
Effect of Composition and Surface Type on Activity of Transition Metal Oxides and Sulfides for $\mathrm{CO}_{2}$ Electrochemical Reduction
}

\author{
Sahithi Ananthaneni ${ }^{\mathrm{a}}$, Rees B Rankin ${ }^{\mathrm{a}, *}$ \\ ${ }^{a}$ Chemical and Biological Engineering, Villanova University, White Hall, 800 E Lancaster Ave, Villanova \\ University, Villanova, 19085, PA, USA
}

\begin{abstract}
Transition metal oxides (TMO) and transition metal sulfides (TMS) are proven to be promising electrocatalysts for $\mathrm{CO}_{2} \mathrm{RR}$ but there is no clear understanding on catalyst activity or product selectivity based on trends in binding free energies. Therefore, a broader array of TMO and TMS are studied as electrocatalysts for $\mathrm{CO}_{2} \mathrm{RR}$ thus addressing the gap in this field. This work shows how different types of surface facets with same catalyst composition can fine-tune the binding free energies of intermediate species by modifying the active binding site. Here, catalyst activity for $\mathrm{CO}_{2} \mathrm{RR}$ towards formation of 4 different products is computed and compared for different materials with (100), (110) and (111) crystal facets and based on this, product selectivity is determined. Optimal catalyst design strategies for this family of materials are developed using the binding free energies of 4 key intermediate species $\mathrm{COOH}^{*}, \mathrm{CO}^{*}, \mathrm{HCO}^{*}$ and $\mathrm{H}^{*}$. In this study, among the materials studied, $\mathrm{ZnO}$ zincblende (100) is the material that showed highest catalyst activity towards $\mathrm{CO}_{2} \mathrm{RR}$ to $\mathrm{CH}_{3} \mathrm{OH}$ and $\mathrm{CH}_{4}$ while minimizing HER.
\end{abstract}

\section{Introduction}

Energy produced and consumed in various fields ranging from heating homes to manufacturing chemicals rely on fossil fuel usage, thereby increasing the concentration of carbon dioxide and other greenhouse gases in the atmosphere. Therefore, it is important to reduce and recycle the amount of carbon dioxide in the atmosphere. Recent advances in electrochemical reduction of $\mathrm{CO}_{2}$ has opened many promising ways to convert into fuels and value-added chemicals. Despite several developments achieved in this field, it still faces few challenges (1) huge overpotential lowering the efficiency of the process, (2) poor product selectivity resulting in expensive separation processes [1-3]. It is well-known that the selectivity of products via electrochemical reduction of $\mathrm{CO}_{2}$ primarily depends on the type of catalyst (electrode) material. In 1985, Hori et al. reported that among different transition

\footnotetext{
*Corresponding author.

Email address: rb.rankin@villanova.edu (Rees B Rankin)
} 
metals, $\mathrm{Cu}$ is the only metal catalyst which can reduce $\mathrm{CO}_{2}$ to value-added chemicals and additional experimental studies showed that $\mathrm{CO}_{2}$ can produce 16 different products on $\mathrm{Cu}$ among which $\mathrm{CH}_{4}$ and $\mathrm{C}_{2} \mathrm{H}_{4}$ have higher current densities. However, they still suffer from high overpotential of $\sim 1 \mathrm{~V}$ and poor product selectivity. Many theoretical and experimental studies proposed that $\mathrm{CO}_{2}$ reduction to desired products is primarily influenced by the binding strength of $\mathrm{CO}^{*}$ species (* indicates adsorbed species) which helped in providing a basis for designing various catalyst materials for $\mathrm{CO}_{2} \mathrm{RR}\left(\mathrm{CO}_{2}\right.$ reduction reaction) [4-6].

In our previous study on transition metal oxides and sulfides as electrocatalysts for $\mathrm{CO}_{2}$ reduction, $\mathrm{CO}^{*}$ was hypothesized and determined to be the most suitable descriptor via scaling relations and a prototype volcano plot is achieved for $\mathrm{CO}_{2}$ reduction to $\mathrm{CH}_{3} \mathrm{OH}$ and $\mathrm{CH}_{4}$ on TMO and TMS hybrid catalyst materials [7]. This plot presented that $\mathrm{CO}_{2}->$ $\mathrm{COOH}^{*}$ and $\mathrm{CO}^{*}{ }_{-}>\mathrm{HCO}^{*}$ are the two intermediate reaction steps which define the catalyst activity for $\mathrm{CO}_{2} \mathrm{RR}$ to $\mathrm{CH}_{3} \mathrm{OH}$ and $\mathrm{CH}_{4}$. Since catalyst activity is affected by the binding energies of key intermediate species such as $\mathrm{CO}^{*}$, the binding strength of these species can be altered by performing compositional and structural changes to catalyst materials. Inspired by the observations from our previous work, we study $\mathrm{CO}_{2}$ reduction to $\mathrm{CH}_{3} \mathrm{OH}$ and $\mathrm{CH}_{4}$ as major products on a wide range of transition metal oxides and sulfides to understand how modifying active binding sites modify the catalytic efficiency. Typically, two approaches are followed: (1) increase the number of active sites by modifying catalyst surface for reaction to occur at different active sites, (2) increase the intrinsic activity of each active binding site by modifying its composition. Everywhere possible, we compare our methodologies and findings with those in other recent mechanistic studies involving $\mathrm{CO}_{2}$ reduction reaction.

\section{Methods}

\subsection{Theoretical calculations}

In this work, we combine two strategies to select catalyst materials for $\mathrm{CO}_{2}$ reduction. The first one is the use of electronegativity of transition metals as a factor to understand their catalytic nature due to their ability to adsorb and desorb from molecules [8]. Using the Pauling electronegativity scale, transition metals which are closer to the range of electronegative value of $\mathrm{Cu}$ are predicted to perform well as an electrocatalyst for $\mathrm{CO}_{2} \mathrm{RR}$. Another rational strategy for selection of catalysts and enhancing the catalytic performance is the tuning of electronic structure of electrocatalytic transition metals by introducing oxides or sulfides which has a different electronegative value than the transition metal. Because the binding properties of the adsorbate or intermediate species are determined by the electronic properties of the metal (catalyst), that is the nature of the d-band electrons, alloying the metal catalyst with another material is proven to be a powerful approach for designing and tuning $\mathrm{CO}_{2} \mathrm{RR}$ catalyst materials [9-11]. Although alloying provides a direct approach to tuning the binding strength by modifying electronic structure, local structure also plays an important role for modifying catalyst activity [2]. The unique surface environment given by different types of crystal facets of a nanomaterial can control the nature of d-band electrons in a site-specific manner. Based on this idea, we study $\mathrm{CO}_{2} \mathrm{RR}$ on transition metal oxides and sulfides given below and are arranged in the decreasing order of the electronegativity 
of base metal and the materials considered in this study are thermodynamically stable form of W, Mo, Ag, Cu, Co, Zn, Mn oxides and sulfides with (100), (110) and (111) planar surfaces which is developed as a continuation of the previous work [7, 12, 13]. While our work is entirely computational, there are many encouraging experimental observations showing electrochemical $\mathrm{CO}_{2}$ reduction through above mentioned transition metals and their alloys as electrocatalysts and guided us towards the selection of these metals with oxide and sulfide composition [14-20]. In specific, we study $\mathrm{WO}_{3}, \mathrm{MoO}_{3}, \mathrm{Ag}_{2} \mathrm{O}, \mathrm{AgO}, \mathrm{Ag}_{2} \mathrm{~S}, \mathrm{CuO}, \mathrm{Cu}_{2} \mathrm{O}, \mathrm{CuS}$, $\mathrm{Cu}_{2} \mathrm{~S}, \mathrm{Co}_{3} \mathrm{O}_{4}, \mathrm{ZnO}, \mathrm{ZnS}, \mathrm{MnO}, \mathrm{MnO}_{2}$ for $\mathrm{CO}_{2}$ reduction to four different products namely $\mathrm{CO}, \mathrm{HCOOH}, \mathrm{CH}_{3} \mathrm{OH}$ and $\mathrm{CH}_{4}$. Unit cell lattice parameters of each of these materials are given in supplementary information. Plane wave DFT calculations are performed on VASP to find optimized surface structures and calculate electronic structure properties [21-27]. These are performed using Van Der Waals, opt -PBE functional as they do not neglect dispersion forces with gamma centered k-points mesh of $2 \times 2 \times 1$ and Fermi smearing of 0.2 $\mathrm{eV}$ is used. The convergence of ground state energies is set to less than $10^{-5} \mathrm{eV} / \mathrm{mole}$-unit cell with respect to k-point sampling. A vacuum space of $12 \AA$ is defined to minimize the interactions between repeated slabs. Each intermediate is analyzed in top, bridge, FCC hollow and hcp hollow (wherever applicable) sites to find out the active site (the lowest energy formation site). All the reaction energy calculations are accomplished using the lowest energy conformation of the intermediate species with solvation effect into consideration. We have used implicit solvation model into the plane-wave DFT code throughout this work with water dielectric constant of 78.4 to describe the interactions between solute (intermediate species) and solvent (water).

\subsection{Reaction network}

In previous work a prototype volcano plot is achieved which shows that the two steps, $\mathrm{CO}_{2}$ protonation and $\mathrm{CO}^{*}$ protonation are the key intermediate steps which determine the catalyst activity and product selectivity i.e. if a particular catalyst material can reduce $\mathrm{CO}_{2}$ to $\mathrm{CH}_{3} \mathrm{OH}$ and $\mathrm{CH}_{4}$ on TMO and TMS materials. The first three intermediate reaction steps in $\mathrm{CO}_{2} \mathrm{RR}$ are shown below:

Step 1: $\mathrm{CO}_{2}+\left(\mathrm{H}^{+}+e^{-}\right) \rightarrow \mathrm{COOH}^{*}$

Step 2: $\mathrm{COOH}^{*}+\left(\mathrm{H}^{+}+e^{-}\right) \rightarrow \mathrm{CO}^{*}+\mathrm{H}_{2} \mathrm{O}$ or $\mathrm{COOH}^{*}+\left(\mathrm{H}^{+}+e^{-}\right) \rightarrow \mathrm{HCOOH}$

Step 3: $\mathrm{COOH}^{*}+\left(\mathrm{H}^{+}+e^{-}\right) \rightarrow \mathrm{CO}^{*}+\mathrm{H}_{2} \mathrm{O}$

At step 2, based on the binding strength of $\mathrm{CO}^{*}$, the reaction can further proceed to form hydrocarbon fuels and value-added chemicals or can evolve as CO gas and depending on the binding free energies of formation of $\mathrm{CO}^{*}$ and $\mathrm{HCOOH}$, one product is preferred over the other. Binding energy of each adsorbate species is calculated by:

$E_{\text {binding }}=E_{D F T}-\left(E_{\text {surface }}+x E_{C}+y E_{H}+z E_{O}\right)$

$\mathrm{E}_{D F T}$ is the DFT energy of the intermediate species adsorbed onto the surface of the catalyst; $\mathrm{E}_{\text {surface }}$ is the energy of the bare surface; $\mathrm{E}_{C}, \mathrm{E}_{H}$, and $\mathrm{E}_{O}$ are the energies of $\mathrm{C}, \mathrm{H}$, and $\mathrm{O}$ atom, respectively, calculated from gaseous $\mathrm{CO}, \mathrm{H}_{2}$, and $\mathrm{H}_{2} \mathrm{O}$. Using Norskov's CHE method, free energies of formation of each of the reaction step along the reaction network are computed with RHE (reversible hydrogen electrode) as the reference electrode for all the reactions [28] Other reactions such as ORR, HER which involve proton-electron transfer 
steps are also studied in the same fashion. Since it is tedious to computationally calculate the chemical potential of each proton-electron pair, we assume that protons and electrons are in equilibrium with one $\mathrm{H}_{2}$ molecule at zero potential $(\mathrm{U}=0), \mathrm{pH}=0, \mathrm{~T}=300 \mathrm{~K}$ and $\mathrm{P}\left(\mathrm{H}_{2}\right)=1$ ATM as shown below.

$\frac{1}{2} H_{2} \leftrightarrow\left(H^{+}+e^{-}\right)$ by:

Binding free energy of formation of the first three steps in reaction network are calculated

$$
\begin{aligned}
& \Delta G_{C O O H^{*}}=G_{C O O H^{*}}-\left(G_{C O_{2}}+G_{0.5 H_{2}}\right) \\
& \Delta G_{C O^{*}}=G_{C O^{*}}+G_{H_{2} O}-\left(G_{C O O H^{*}}+G_{0.5 H_{2}}\right) \\
& \Delta G_{H C O^{*}}=G_{H C O^{*}}-\left(G_{C O^{*}}+G_{0.5 H_{2}}\right)
\end{aligned}
$$

\subsection{Screening based on binding free energies of $\mathrm{CO}^{*}$}

Catalyst activity and product selectivity can be predicted by analyzing the binding free energies of descriptor on each of the catalyst material. From our previous studies on TMO and TMS materials as electrocatalysts for $\mathrm{CO}_{2} \mathrm{RR}$, we identified $\mathrm{CO}^{*}$ as the descriptor using Sabatier's activity volcano plot. The binding free energy of $\mathrm{CO}^{*}$ (descriptor) from this prototype volcano plot is $-0.25 \mathrm{eV}$. Materials with stronger $\mathrm{CO}^{*}$ binding free energies block the active sites of the surface of the catalyst and require higher over potential to further reduce to $\mathrm{CH}_{3} \mathrm{OH}$ and $\mathrm{CH}_{4}$. Those materials closer to the optimum binding free energies of $\mathrm{CO}^{*}$ bind to the surface of the catalyst and are expected to further reduce to products with minimum theoretical overpotentials. Those materials with weaker binding free energies of $\mathrm{CO}^{*}$ desorb immediately as gaseous $\mathrm{CO}$ as they are limited by the activation of reactants. As a first step towards screening, we calculate binding energies of $\mathrm{CO}^{*}$ on all the materials considered in this study i.e. $\mathrm{WO}_{3}, \mathrm{MoO}_{3}, \mathrm{Ag}_{2} \mathrm{O}, \mathrm{AgO}, \mathrm{Ag}_{2} \mathrm{~S}, \mathrm{CuO}, \mathrm{Cu}_{2} \mathrm{O}, \mathrm{CuS}$, $\mathrm{Cu}_{2} \mathrm{~S}, \mathrm{Co}_{3} \mathrm{O}_{4}, \mathrm{ZnO}, \mathrm{ZnS}, \mathrm{MnO}, \mathrm{MnO}_{2}$ with (100), (110) and (111) type of surfaces. From this pool, only those materials which showed binding free energy of $\mathrm{CO}^{*}$ with a magnitude of $1.5 \mathrm{eV}$ from the optimal binding free energy obtained from prototype volcano plot are studied. Those materials which fall away from the optimum binding energy range either due to too strong or too weak binding of $\mathrm{CO}^{*}$ are eliminated.

\section{Results and discussion}

\subsection{Scaling relations and volcano plots: $\mathrm{CH}_{3} \mathrm{OH}$ and $\mathrm{CH}_{4}$ as products}

Scaling relations are obtained correlating binding free energies of $\mathrm{CO}^{*}$ with $\mathrm{COOH}^{*}$ and $\mathrm{HCO}^{*}$ respectively for transition metal oxides and transition metal sulfide type of catalysts. These plots are shown in supplementary information. It is important to remember that $\mathrm{CO}^{*}$ does not bind to single type of active binding site on all transition metal oxide and transition metal sulfide materials. Hence, it is common to have scatter in our scaling plots. If the materials have perfect linear scaling relations like in pure metals, then methane or methanol are the only products formed. Since our scaling relations have slight scatter, CO* is predicted to reduce a mixture of products at a certain reducing potential. That is, the competing reaction pathways in $\mathrm{CO}_{2} \mathrm{RR}$ can generate a variety of chemically- similar bound 
intermediates. These intermediates can form more than one product at a given reducing potential.

The binding free energy of formation of $\mathrm{COOH}^{*}$ and $\mathrm{HCO}^{*}$ intermediate species in the reaction network can be related to that of descriptor, $\mathrm{CO}^{*}$ by the equations given below. These equations allow us to write limiting potential of each step as a function of $\mathrm{CO}^{*}$ binding free energy.

$$
\begin{aligned}
& \Delta G_{C O O H^{*}}=-0.80 \Delta G_{C O^{*}}-0.35 \mathrm{eV} \\
& \Delta G_{H C O^{*}}=-0.97 \Delta G_{C O^{*}}-0.03 \mathrm{eV}
\end{aligned}
$$

As we know $\mathrm{CO}_{2}->\mathrm{COOH}^{*}$ and $\mathrm{CO}^{*}>\mathrm{HCO}^{*}$ are the two intermediate reaction steps which are potential limiting defining the catalyst activity, the above scaling relation equations are used to construct a comprehensive volcano plot comparing the activity of transition metal oxide and sulfide type of catalysts for $\mathrm{CO}_{2} \mathrm{RR}$. For a clear understanding, separate volcano plots for (100), (110) and (111) crystal facets are shown. Limiting/reducing potential of each catalyst material for $\mathrm{CO}_{2}$ reduction to products is given by the corresponding $\mathrm{y}$-axis value in the volcano plots. In Figures 1, 2 and 3 the difference between equilibrium potential of $\mathrm{CH}_{3} \mathrm{OH}$ and $\mathrm{CH}_{4}$ represented by dotted lines and reducing potential obtained for a catalyst material from the volcano shaped lines is the minimum theoretical overpotential required for reduction of $\mathrm{CO}_{2}$ to $\mathrm{CH}_{3} \mathrm{OH}$ or $\mathrm{CH}_{4}$. $\mathrm{CO}^{*}$ binding free energy at the peak of the volcano is defined as the optimum binding energy. The optimum $\Delta \mathrm{G}\left(\mathrm{CO}^{*}\right)$ for the transition metal oxide and transition metal sulfide type of catalysts with low miller index surfaces is $-0.28 \mathrm{eV}$. An important idea here is the optimum binding free energy of $\mathrm{CO}^{*}$ from prototype volcano plot obtained in previous studies is $-0.25 \mathrm{eV}$ for six different materials with (100) type of crystal facet whereas the updated volcano plot displays optimum binding free energy of $\mathrm{CO}^{*}$ as $-0.28 \mathrm{eV}$ for ten different materials with 3 different crystal facets. Comparing the optimum $\Delta \mathrm{G}\left(\mathrm{CO}^{*}\right)$ from these two volcano plots, there has been a shift in the binding free energy of $\mathrm{CO}^{*}$ towards left by only $-0.03 \mathrm{eV}$. This means, addition of materials to the volcano plot will not qualitatively modify the conclusions reached based on the optimum binding free energy range of $\mathrm{CO}^{*}$ but quantitatively there will be a slight shift in the peak of the volcano. This key result supports that this comprehensive volcano plot comparing the activity of a wide range of transition metal oxides and sulfides can be used as a basis to improve the activity of current catalysts or explore new catalysts for $\mathrm{CO}_{2} \mathrm{RR}$.

Those materials which have too strong $\mathrm{CO}^{*}$ binding free energies require higher potentials for further reduction and those which have too weak binding free energies prefer $\mathrm{CO}_{(g)}$ as product. Since there are not enough experimental observations for all the materials studied here, there will be tiny amount of uncertainty on the predicted reducing potential and hence the activity. Therefore, an optimum binding free energy range is defined with a magnitude of $\sim 0.3 \mathrm{eV}$ w.r.t to optimum $\Delta \mathrm{G}\left(\mathrm{CO}^{*}\right)$ and the materials that fall in this binding free energy range are predicted to show improved catalyst activity towards $\mathrm{CO}_{2}$ reduction to $\mathrm{CH}_{3} \mathrm{OH}$ and $\mathrm{CH}_{4}$. These materials along with their descriptor, CO* binding free energies are tabulated below.

This table also shows how different surfaces of same catalyst composition can modify the reducing potential required for desired product formation based on how strong or ' the interactions of intermediates are with the surface of the catalyst. Modifying the surface type 


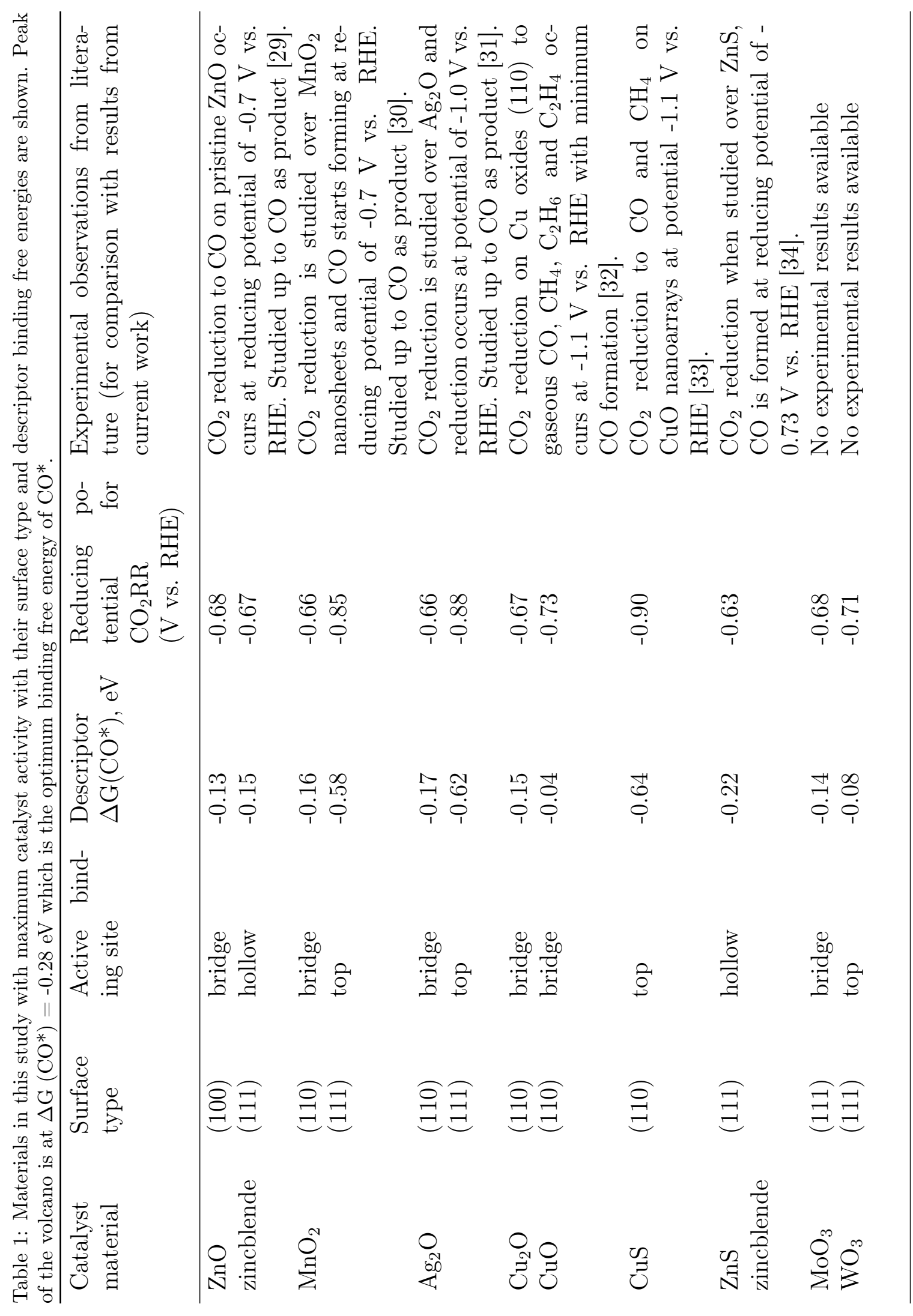




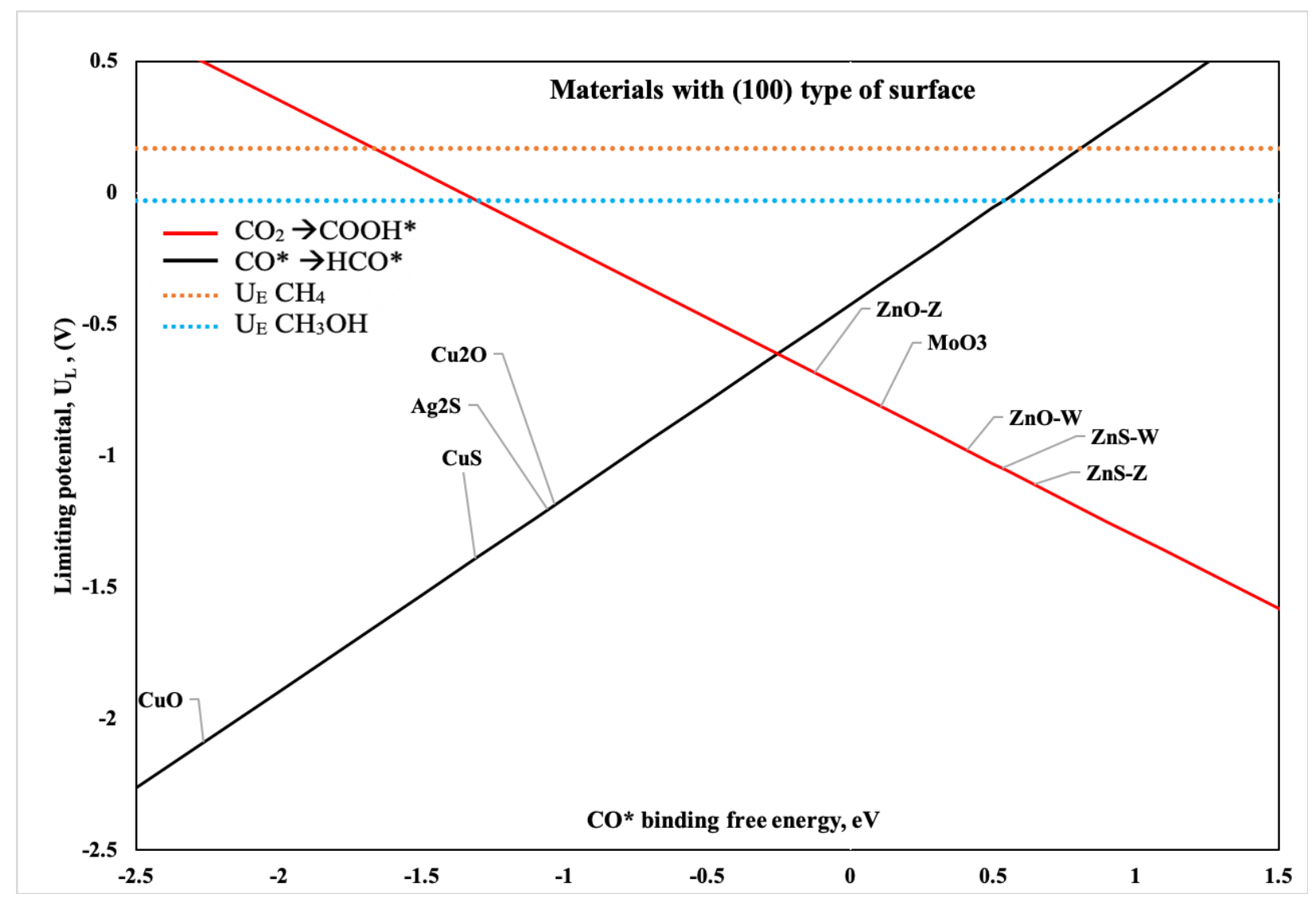

Figure 1: Volcano plot depicting catalyst activity of various materials in terms of limiting potential and CO* binding free energy for materials with (100) type of surface

will fine-tune the binding free energies by modifying the active binding sites. For instance, $\mathrm{MnO}_{2}$ (110) holds a descriptor binding free energy of $-0.16 \mathrm{eV}$ on bridge site whereas $\mathrm{MnO}_{2}$ (111) holds a descriptor binding free energy of $-0.58 \mathrm{eV}$ on top site. Modifying the surface type modified the $\Delta \mathrm{G}\left(\mathrm{CO}^{*}\right)$ by $\sim 0.4 \mathrm{eV}$. However, $\mathrm{ZnO}$ with (100) and (111) surfaces displays minor difference in binding free energies of descriptor and for this reason, the minimum reducing potential required for $\mathrm{CO}_{2}$ reduction to $\mathrm{C}_{1}$ products on $\mathrm{ZnO}(100)$ and (111) are similar. This table compares experimental observations from literature with the results from current work. There has been very limited study about overpotentials required for $\mathrm{CO}_{2}$ reduction to $\mathrm{CH}_{3} \mathrm{OH}$ and $\mathrm{CH}_{4}$ on transition metal oxides and sulfides. As seen from the table, most of the theoretical and experimental studies on promising catalyst materials were conducted only up to $\mathrm{CO}$ formation, and $\mathrm{CO}_{2}$ reduction to $\mathrm{CH}_{3} \mathrm{OH}$ and $\mathrm{CH}_{4}$ beyond $\mathrm{Cu}$ compositions is barely explored. This explains why current work on $\mathrm{CO}_{2} \mathrm{RR}$ via transition metal oxides and sulfides to $\mathrm{CH}_{3} \mathrm{OH}$ and $\mathrm{CH}_{4}$ is significant.

\section{2. $\mathrm{HCOOH}$ formation}

At the first proton electron transfer, $\mathrm{CO}_{2}$ can either reduce to $\mathrm{COOH}^{*}$ or $\mathrm{OCHO}^{*}$. From literature and our previous work on transition metal oxides and sulfides, if $\mathrm{COOH}^{*}$ 


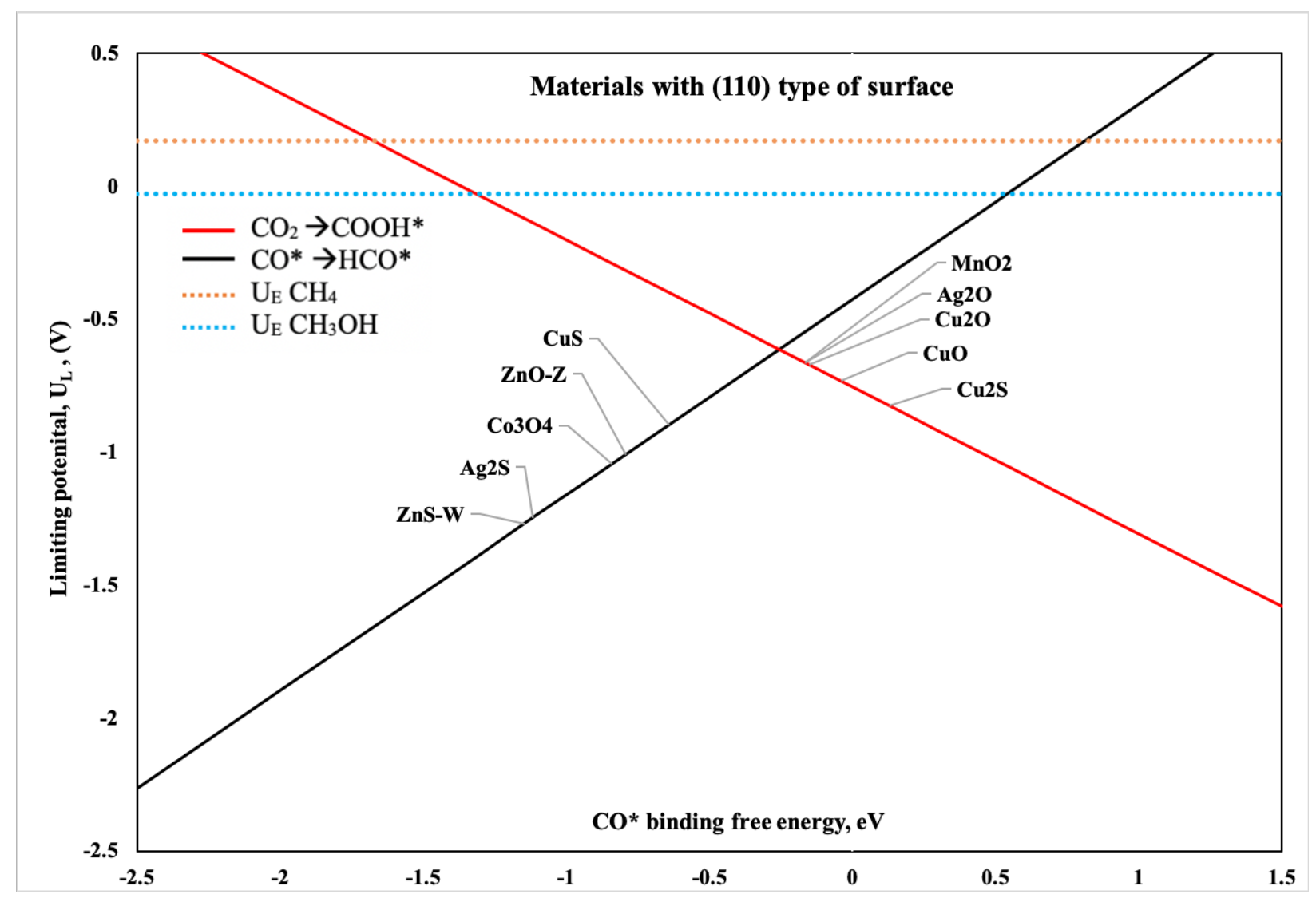

Figure 2: Volcano plot depicting catalyst activity of various materials in terms of limiting potential and $\mathrm{CO}^{*}$ binding free energy for materials with (110) type of surface

is preferred over $\mathrm{OCHO}^{*}$ for $\mathrm{CO}_{2}$ reduction, the material favors $\mathrm{CO}, \mathrm{CH}_{3} \mathrm{OH}$ and $\mathrm{CH}_{4}$ as products. However, if $\mathrm{OCHO}^{*}$ is preferred, the transition metal oxide catalysts show improved activity and selectivity towards $\mathrm{HCOOH}$ formation. All the materials selected in this study preferred $\mathrm{COOH}^{*}$ over $\mathrm{OCHO}^{*}$, hence these are more favorable towards $\mathrm{CO}$, $\mathrm{CH}_{3} \mathrm{OH}$ and $\mathrm{CH}_{4}$ formation at lower reducing potentials. Figure 4 compares reducing potential required for $\mathrm{HCOOH}$ formation on catalysts that showed highest activity towards $\mathrm{CO}_{2} \mathrm{RR}$ in this study (presented in Table 1). This figure clearly shows $\mathrm{HCOOH}$ formation occurs at higher reducing potentials compared to $\mathrm{CO}_{2}$ reduction to $\mathrm{CO}, \mathrm{CH}_{3} \mathrm{OH}$ and $\mathrm{CH}_{4}$ formation (shown in Table 1). Based on this result it is confirmed that across different binding energy regime, among the pool of materials studied for current reduction reaction, the catalyst materials prefer $\mathrm{COOH}^{*}$ over $\mathrm{OCHO}^{*}$ and hence do not favor formic acid formation at low reducing potentials.

\subsection{Design strategies for TMO and TMS electrocatalysts for $\mathrm{CO}_{2} \mathrm{RR}$}

While the catalyst materials tabulated above showed better activity towards $\mathrm{CO}_{2} \mathrm{RR}$, it is important to understand hydrogen evolution reaction (HER) as thermodynamically both the reactions occur closer to $0 \mathrm{~V}$ and $\mathrm{H}_{2}$ formation is kinetically easy reaction to occur. Therefore, 


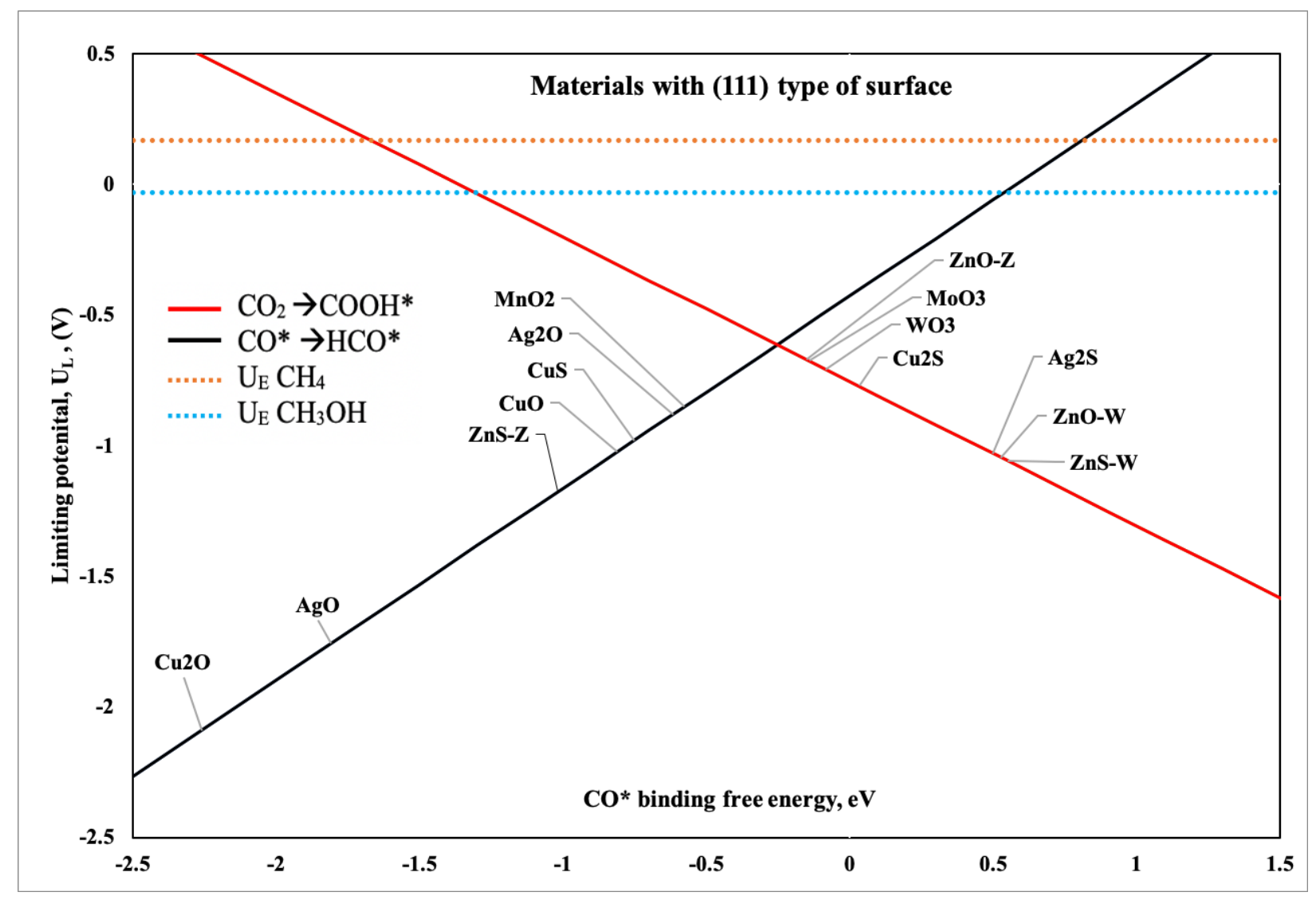

Figure 3: Volcano plot depicting catalyst activity of various materials in terms of limiting potential and $\mathrm{CO}^{*}$ binding free energy for materials with (111) type of surface

minimizing $\mathrm{H}_{2}$ without compromising with the catalyst activity is a major challenge in $\mathrm{CO}_{2}$ electroreduction process. In order to understand if $\mathrm{CO}_{2}$ reduction is preferred over hydrogen evolution reaction (HER) on the catalysts systems without compromising with the product selectivity and catalyst activity, various design strategies are proposed which are mentioned below based on the results achieved so far. The design strategies adopted in this work are generally applicable towards designing other metal oxide and sulfide type of electrocatalysts or improving current catalyst systems for $\mathrm{CO}_{2} \mathrm{RR}$.

- $\mathrm{COOH}^{*}$ is supposed to bind stronger than $\mathrm{H}^{*}$ and at the same time $\mathrm{COOH}^{*}$ should bind weak enough to further reduce to $\mathrm{CO}^{*}$ at lower potential. Quantitatively, $\Delta \mathrm{G}\left(\mathrm{CO}^{*}\right)<\Delta \mathrm{G}\left(\mathrm{COOH}^{*}\right)<\Delta \mathrm{G}\left(\mathrm{H}^{*}\right)$.

- $\mathrm{CO}^{*}$ should bind to the surface within optimum binding free energy range and $\mathrm{H}^{*}$ should bind to the surface with positive binding free energy to limit $\mathrm{CO}(\mathrm{g})$ and $\mathrm{H}_{2}(\mathrm{~g})$ formation and enhance $\mathrm{CH} 3 \mathrm{OH}$ and $\mathrm{CH} 4$ formation.

- Reducing or limiting potential of $\Delta \mathrm{G}\left(\mathrm{CO}^{*}\right.$ ) formation step (y-axis value of volcano plots in Figure 1) should be minimum. 


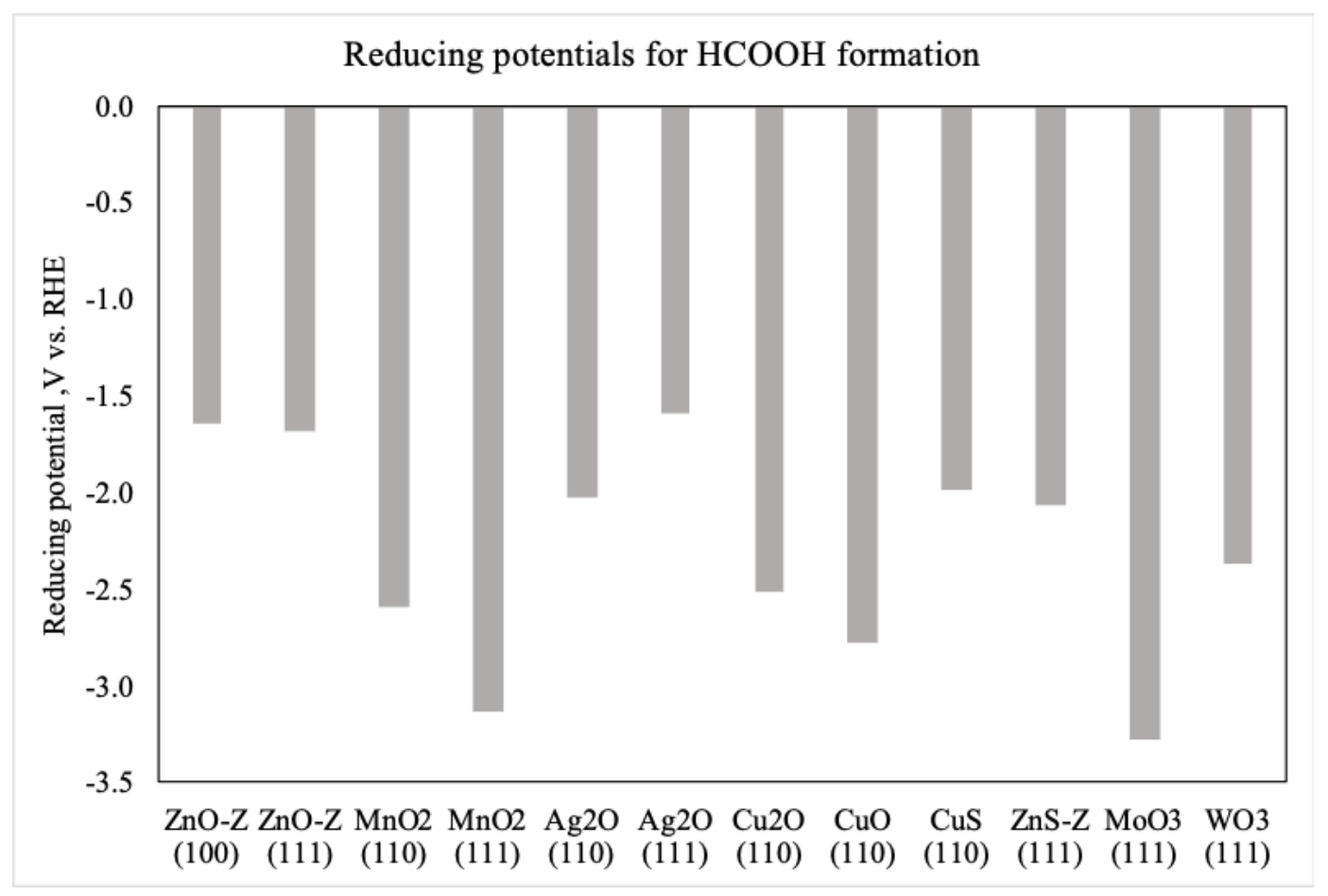

Figure 4: Comparison of reducing potential required for $\mathrm{HCOOH}$ formation on catalyst materials which showed highest activity towards $\mathrm{CO}_{2}$ reduction to $\mathrm{CO}, \mathrm{CH}_{3} \mathrm{OH}$ and $\mathrm{CH}_{4}$.

\section{4. $\mathrm{COOH}^{*}$ vs. $\mathrm{H}^{*}$}

As the first proton-electron comes into contact with the reactant, $\mathrm{CO}_{2}$ should form $\mathrm{COOH}^{*}$ suppressing $\mathrm{H}_{2}$ formation from $\mathrm{H}^{*}$. This happens when $\mathrm{COOH}^{*}$ is more stable compared to $\mathrm{H}^{*}$. Simultaneously, $\mathrm{COOH}^{*}$ should not bind too strong or the protonation of $\mathrm{COOH}^{*}$ to form $\mathrm{CO}^{*}$ will be too difficult favoring $\mathrm{H}_{2}$ formation from $\mathrm{H}^{*}$. Figure 5 compares binding free energies of $\mathrm{COOH}^{*}$ and $\mathrm{H}^{*}$ intermediate species on different transition metal oxide and sulfide type of catalyst materials. The plot is divided into four quadrants based on the binding free energies of $\mathrm{COOH}^{*}$ and $\mathrm{H}^{*}$ and the materials which fall in green quadrant with weak $\mathrm{COOH}^{*}$ and weak $\mathrm{H}^{*}$ binding free energies show a promising area for $\mathrm{CO}_{2}$ reduction to $\mathrm{CH}_{3} \mathrm{OH}$ and $\mathrm{CH}_{4}$. Among the materials which showed highest catalyst activity (from Table 1), those that fall in this region are $\mathrm{ZnO}$ zincblende (100), $\operatorname{Ag}_{2} \mathrm{O}$ (111). The materials in red quadrant have strong $\mathrm{COOH}^{*}$ and strong $\mathrm{H}^{*}$ and the materials having either strong $\mathrm{COOH}^{*}$ or strong $\mathrm{H}^{*}$ are shown in blue quadrants and these materials although cannot reduce $\mathrm{CO} 2$ at lower potentials by minimizing HER, they can be studied further by modifying the composition to improve their activity. The materials that fall in these regions with strong $\mathrm{COOH}^{*}$ binding free energy region require high overpotentials for further reduction to products and those materials that fall within strong $\mathrm{H}^{*}$ binding free energy region are favorable towards $\mathrm{CO}$ formation than further $\mathrm{CO}^{*}$ reduction to $\mathrm{CH}_{3} \mathrm{OH}$ and $\mathrm{CH}_{4}$. 


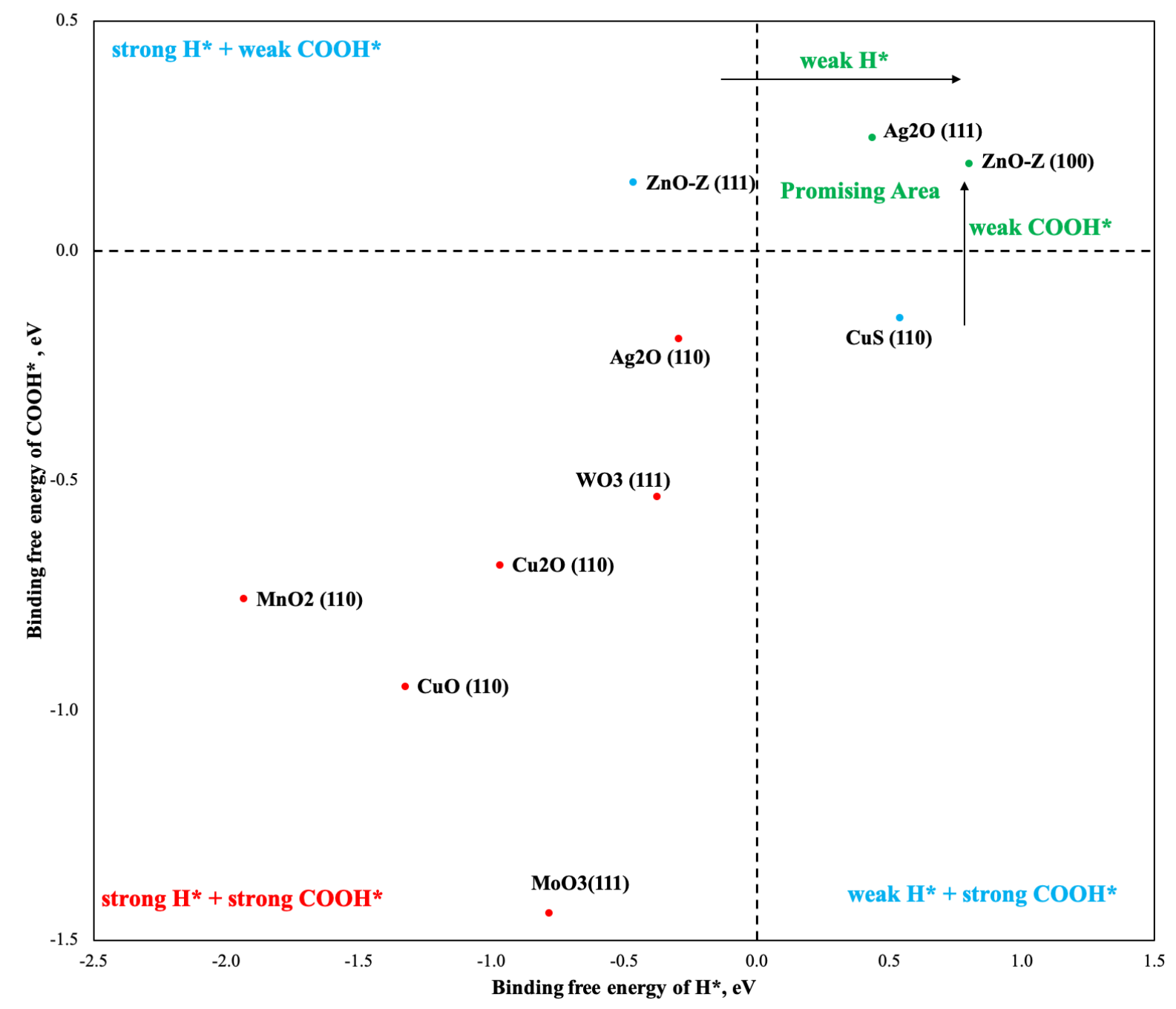

Figure 5: Binding free energies of $\mathrm{COOH}^{*}$ vs $\mathrm{H}^{*}$ intermediate species on transition metal oxide and sulfide type of catalyst materials which showed the highest activity among the pool of materials in our study. The plot is divided into 4 quadrants and the materials which fall in green quadrant with weak $\mathrm{COOH}^{*}$ and weak $\mathrm{H}^{*}$ binding free energies show a promising area for $\mathrm{CO}_{2}$ reduction to $\mathrm{CH}_{3} \mathrm{OH}$ and $\mathrm{CH}_{4}$.

\section{5. $C O^{*}$ vs. $H^{*}$}

The aim of our study is to convert $\mathrm{CO}_{2}$ into $\mathrm{CH}_{3} \mathrm{OH}$ and $\mathrm{CH}_{4}$ on transition metal oxide and sulfide type of catalysts. To achieve this, $\mathrm{CO}_{(g)}$ and $\mathrm{H}_{2(g)}$ formation should be limited. Therefore, $\mathrm{CO}^{*}$ must bind to the surface of the catalyst within optimum binding free energy range obtained from the volcano plot and $\mathrm{H}^{*}$ should bind to the surface of the catalyst with positive binding free energy.

In Figure 4, $\mathrm{CO}^{*}$ binding free energy is plotted as a function of the $\mathrm{H}^{*}$ binding free energy to and all the materials considered in this study are divided into three categories 


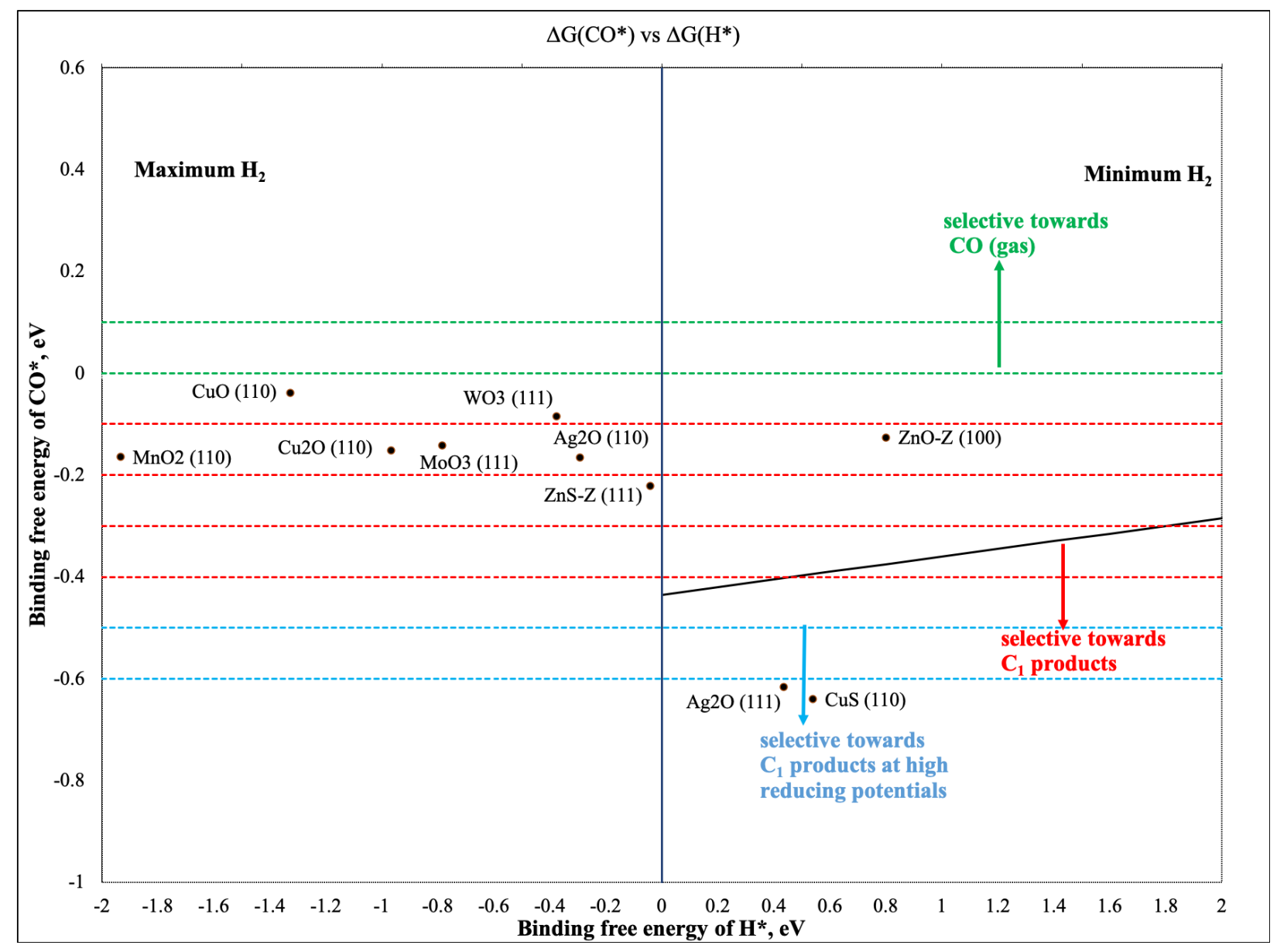

Figure 6: Linear relation between binding free energies of $\mathrm{CO}^{*}$ and $\mathrm{H}^{*}$. Green dotted lines depict weak $\Delta \mathrm{G}$ $\left(\mathrm{CO}^{*}\right)$, blue dotted lines depict strong $\Delta \mathrm{G}\left(\mathrm{CO}^{*}\right)$ region and red dotted lines depict optimum $\Delta \mathrm{G}\left(\mathrm{CO}^{*}\right)$ region. Black solid line is the linear scaling line relating binding free energies of $\mathrm{CO}^{*}$ and $\mathrm{H}^{*}$. Vertical blue solid line separates materials into two categories:strong(negative) $\mathrm{H}^{*}$ binding free energy and weak (positive) $\mathrm{H}^{*}$ binding freeenergies.

based on the product formed. Blue region shown in the figure is denoted as stronger binding free energy region of $\mathrm{CO}^{*}$ and will cause further reduction of $\mathrm{CO}^{*}$ but this occurs at higher overpotentials. Red binding free energy region in the figure is shown as the optimum binding free energy range and the materials that fall in this area are the promising materials in current study as these can further reduce to $\mathrm{CH}_{3} \mathrm{OH}$ and $\mathrm{CH}_{4}$ as products at lower reducing potentials. Weaker binding free energy region is shown by green region and materials in this region have weak $\Delta \mathrm{G}\left(\mathrm{CO}^{*}\right)$ favoring $\mathrm{CO}_{(g)}$ formation with minimum amount of $\mathrm{CH}_{3} \mathrm{OH}$ and $\mathrm{CH}_{4}$. In the figure, materials towards the left of solid blue line at $\Delta \mathrm{G}\left(\mathrm{H}^{*}\right)<0 \mathrm{eV}$ are selective towards $\mathrm{C}_{1}$ products and $\mathrm{H}_{2}$ because of strong (negative) $\mathrm{H}^{*}$ binding free energy. Materials towards right of solid blue line i.e. $\Delta \mathrm{G}\left(\mathrm{H}^{*}\right)>0 \mathrm{eV}$ are selective towards $\mathrm{C}_{1}$ products while minimizing $\mathrm{H}_{2}$ formation because of poor/positive $\mathrm{H}^{*}$ binding free energies. Therefore, the materials that have positive $\mathrm{H}^{*}$ binding free energy (right of black dotted 
line) and falls in red binding free energy region are the most promising ones. Among the materials studied in this work, $\mathrm{ZnO}$ zincblende (100) is the material that satisfy this criterion and is located in this active and selective area. This is supported by findings from literature which shows that $\mathrm{ZnO}$ type of materials could be a potential catalyst for $\mathrm{CO}_{2}$ reduction to $\mathrm{CO}$ at $-0.62 \mathrm{~V}$ vs.RHE with Faradaic efficiency $>90 \%$ [35].

It is important to understand that from volcano shaped activity plots achieved in Figures 1,2 and 3, ZnS zincblende (111) showed highest activity among the pool of materials studied in this work for $\mathrm{CO}_{2} \mathrm{RR}$. While combining this result with our design strategies and binding free energy analysis, this catalyst material has also proven to show decent activity towards HER. Since, the goal of an optimum catalyst for $\mathrm{CO}_{2} \mathrm{RR}$ is to have increased catalyst activity towards formation of $\mathrm{C}_{1}$ products as well as minimize HER, $\mathrm{ZnO}$ zincblende (100) is a promising catalyst for $\mathrm{CO}_{2} \mathrm{RR}$ as this has shown higher catalyst activity towards $\mathrm{CH}_{3} \mathrm{OH}$ and $\mathrm{CH}_{4}$ formation simultaneously minimizing HER.

\section{Conclusions}

Transition metals as electrocatalysts has been extensively studied for $\mathrm{CO}_{2} \mathrm{RR}$, but the properties of metal oxides and metal sulfides, although shown to be potentially promising, are much less well understood. So far there haven't been any clear understanding of design rules or reaction mechanism trends for this family of electrocatalysts. In this work, a broader array of transition metal oxide (TMO) and transition metal-sulfides (TMS) electro-catalysts are studied as electrocatalysts for $\mathrm{CO}_{2} \mathrm{RR}$ thus addressing the gap in this field. An in-depth understanding of $\mathrm{CO}_{2}$ reduction to $\mathrm{CH}_{3} \mathrm{OH}$ and $\mathrm{CH}_{4}$ on TMO and TMS by constructing comprehensive volcano shaped activity plots which ranks the activity of catalysts based on descriptor $\left(\mathrm{CO}^{*}\right)$ binding free energy is achieved. This work also demonstrated how different surfaces of same catalyst composition can fine-tune the binding free energies by modifying the active binding site. Catalyst activity for $\mathrm{CO}_{2} \mathrm{RR}$ towards 4 different products is computed and compared for different materials with (100), (110) and (111) crystal facets. Optimal catalyst design strategies based on binding free energies of 4 important intermediate species $\mathrm{COOH}^{*}, \mathrm{CO}^{*}, \mathrm{HCO}^{*}$ and $\mathrm{H}^{*}$ are developed while dividing the catalysts into 3 categories based on the possibility of most favorable product formed on each surface: $\mathrm{CO}$ (gas) formation, $\mathrm{C}_{1}$ products with minimum $\mathrm{H}_{2}$ formation and just $\mathrm{C}_{1}$ products but at higher reducing potentials. These strategies help in quick identification of possible good candidates for $\mathrm{CO}_{2} \mathrm{RR}$. In this work, binding free energy analysis shows there is a very specific and small region of space (green quadrant) with the most promising performance for $\mathrm{CO}_{2} \mathrm{RR}$ and among the materials studied in this work, $\mathrm{ZnO}$ zincblende (100) is the material that falls in this quadrant and therefore is a promising catalyst towards $\mathrm{CO}_{2} \mathrm{RR}$ to $\mathrm{CH}_{3} \mathrm{OH}$ and $\mathrm{CH}_{4}$ while minimizing HER. It is always possible to enhance the activity of this promising candidate by further modifying the composition either by creating oxygen vacancies or via single-element doping. All in all, this work aims to contribute to theoretical research on activity of transition metal/p-block materials especially transition metal oxide and sulfide type of materials. 


\section{Acknowledgments}

R.B.R. gratefully acknowledges financial and research support from the Department of Chemical Engineering at Villanova University through his startup package fund. S.A. acknowledges financial support from the Department of Chemical Engineering and the College of Engineering at Villanova University as well. We acknowledge the Center for Nanoscale Materials, an Office of Science user facility, supported by the U.S. Department of Energy, Office of Science, Office of Basic Energy Sciences, under Contract no. DEAC02-06CH11357 for the use of Carbon cluster to perform calculations requiring high computing power and assistance from U.N.I.T. team at Villanova University for maintenance of computational resources necessary in this work.

\section{References}

[1] S. Ma, P. J. Kenis, Electrochemical conversion of CO2 to useful chemicals: current status, remaining challenges, and future opportunities, Current Opinion in Chemical Engineering 2 (2) (2013) 191-199.

[2] W. J. Durand, A. A. Peterson, F. Studt, F. Abild-Pedersen, J. K. Nørskov, Structure effects on the energetics of the electrochemical reduction of CO2 by copper surfaces, Surface Science 605 (15-16) (2011) 1354-1359.

[3] M. Karamad, H. A. Hansen, J. Rossmeisl, J. K. Nørskov, Mechanistic pathway in the electrochemical reduction of CO2 on RuO2, ACS Catalysis 5 (7) (2015) 4075-4081.

[4] M. R. Gonçalves, A. Gomes, J. Condeço, R. Fernandes, T. Pardal, C. A. C. Sequeira, J. B. Branco, Selective electrochemical conversion of $\mathrm{CO} 2$ to $\mathrm{C} 2$ hydrocarbons, Energy conversion and management 51 (1) (2010) 30-32.

[5] Y. Hori, K. Kikuchi, S. Suzuki, Production of CO and CH4 in electrochemical reduction of CO2 at metal electrodes in aqueous hydrogencarbonate solution, Chemistry Letters 14 (11) (1985) 1695-1698.

[6] K. P. Kuhl, E. R. Cave, D. N. Abram, T. F. Jaramillo, New insights into the electrochemical reduction of carbon dioxide on metallic copper surfaces, Energy \&amp; Environmental Science 5 (5) (2012) 7050-7059.

[7] S. Ananthaneni, R. B. Rankin, Computational screening of transition metal/p-block hybrid electrocatalysts for CO2 reduction, Journal of Computational Chemistry 41 (14) (2020) 1384-1394.

[8] C. Nwosu, An electronegativity approach to catalytic performance, Journal of Technical Science and Technologies 1 (2) (2012) 25-28.

[9] P. Hirunsit, W. Soodsawang, J. Limtrakul, CO2 electrochemical reduction to methane and methanol on copper-based alloys: theoretical insight, The Journal of Physical Chemistry C 119 (15) (2015) 8238-8249.

[10] J. He, N. J. Johnson, A. Huang, C. P. Berlinguette, Electrocatalytic alloys for CO2 reduction, ChemSusChem 11 (1) (2018) 48-57.

[11] Y. Wang, J. Liu, Y. Wang, A. M. Al-Enizi, G. Zheng, Tuning of CO2 reduction selectivity on metal electrocatalysts, Small 13 (43) (2017) 1701809.

[12] G. O. Larrazábal, A. J. Martín, F. Krumeich, R. Hauert, J. Pérez-Ramírez, Solvothermally-Prepared $\mathrm{Cu} 2 \mathrm{O}$ Electrocatalysts for CO2 Reduction with Tunable Selectivity by the Introduction of p-Block Elements, ChemSusChem 10 (6) (2017) 1255-1265.

[13] G. O. Larrazábal, A. J. Martín, J. Perez-Ramirez, Building blocks for high performance in electrocatalytic CO2 reduction: materials, optimization strategies, and device engineering, The journal of physical chemistry letters 8 (16) (2017) 3933-3944.

[14] H. Li, X. Liu, S. Chen, D. Yang, Q. Zhang, L. Song, H. Xiao, Q. Zhang, L. Gu, X. Wang, Edge-Exposed Molybdenum Disulfide with N-Doped Carbon Hybridization: A Hierarchical Hollow Electrocatalyst for Carbon Dioxide Reduction, Advanced Energy Materials 9 (18) (2019) 1900072. 
[15] D. Ren, J. Gao, S. M. Zakeeruddin, M. Grätzel, Bimetallic Electrocatalysts for Carbon Dioxide Reduction, CHIMIA International Journal for Chemistry 73 (11) (2019) 928-935.

[16] W. Luo, J. Zhang, M. Li, A. Züttel, Boosting CO production in electrocatalytic CO2 reduction on highly porous Zn catalysts, ACS Catalysis 9 (5) (2019) 3783-3791.

[17] X. Peng, Y. Chen, Y. Mi, L. Zhuo, G. Qi, J. Ren, Y. Qiu, X. Liu, J. Luo, Efficient Electroreduction CO2 to CO over MnO2 Nanosheets, Inorganic chemistry 58 (14) (2019) 8910-8914.

[18] W. Luc, C. Collins, S. Wang, H. Xin, K. He, Y. Kang, F. Jiao, Ag-Sn bimetallic catalyst with a core-shell structure for CO2 reduction, Journal of the American chemical society 139 (5) (2017) 1885-1893.

[19] S. Ananthaneni, Z. Smith, R. B. Rankin, Graphene Supported Tungsten Carbide as Catalyst for Electrochemical Reduction of CO2, Catalysts 9 (7) (2019) 604.

[20] X. Nie, W. Luo, M. J. Janik, A. Asthagiri, Reaction mechanisms of CO2 electrochemical reduction on $\mathrm{Cu}\left(\begin{array}{lll}1 & 1 & 1\end{array}\right)$ determined with density functional theory, Journal of catalysis 312 (2014) 108-122.

[21] M. J. Piotrowski, C. G. Ungureanu, P. Tereshchuk, K. E. Batista, A. S. Chaves, D. Guedes-Sobrinho, J. L. D. Silva, Theoretical study of the structural, energetic, and electronic properties of 55-atom metal nanoclusters: A DFT investigation within van der Waals corrections, spin-orbit coupling, and PBE + U of 42 metal systems, The Journal of Physical Chemistry C 120 (50) (2016) 28844-28856.

[22] S. Gautier, S. N. Steinmann, C. Michel, P. Fleurat-Lessard, P. Sautet, Molecular adsorption at Pt (111). How accurate are DFT functionals?, Physical Chemistry Chemical Physics 17 (43) (2015) 28921-28930.

[23] J. Carrasco, J. Klimeš, A. Michaelides, The role of van der Waals forces in water adsorption on metals, The Journal of chemical physics 138 (2) (2013) 024708.

[24] J. Hafner, Materials simulations using VASP - a quantum perspective to materials science, Computer physics communications 177 (1-2) (2007) 6-13.

[25] T. Bucko, J. Hafner, S. Lebegue, J. G. Angyán, Improved description of the structure of molecular and layered crystals: ab initio DFT calculations with van der Waals corrections, The Journal of Physical Chemistry A 114 (43) (2010) 11814-11824.

[26] W. Koch, M. C. Holthausen, A chemist's guide to density functional theory, John Wiley \&amp; Sons, 2015.

[27] W. Kohn, A. D. Becke, R. G. Parr, Density functional theory of electronic structure, The Journal of Physical Chemistry 100 (31) (1996) 12974-12980.

[28] A. A. Peterson, F. Abild-Pedersen, F. Studt, J. Rossmeisl, J. K. Nørskov, How copper catalyzes the electroreduction of carbon dioxide into hydrocarbon fuels, Energy \&amp; Environmental Science 3 (9) (2010) 1311-1315.

[29] Z. Geng, X. Kong, W. Chen, H. Su, Y. Liu, F. Cai, G. Wang, J. Zeng, Oxygen vacancies in ZnO nanosheets enhance $\mathrm{CO} 2$ electrochemical reduction to $\mathrm{CO}$, Angewandte Chemie International Edition 57 (21) (2018) 6054-6059.

[30] X. Peng, Y. Chen, Y. Mi, L. Zhuo, G. Qi, J. Ren, Y. Qiu, X. Liu, J. Luo, Efficient Electroreduction CO2 to CO over MnO2 Nanosheets, Inorganic chemistry 58 (14) (2019) 8910-8914.

[31] M. Yang, J. Zhang, Y. Cao, M. Wu, K. Qian, Z. Zhang, H. Liu, J. Wang, W. Chen, W. Huang, Facet Sensitivity of Capping Ligand-Free Ag Crystals in $\mathrm{CO} 2$ Electrochemical Reduction to CO, ChemCatChem $10(22)(2018) 5128-5134$.

[32] R. Kas, R. Kortlever, A. Milbrat, M. T. Koper, G. Mul, J. Baltrusaitis, Electrochemical CO 2 reduction on $\mathrm{Cu} 2 \mathrm{O}$-derived copper nanoparticles: controlling the catalytic selectivity of hydrocarbons, Physical Chemistry Chemical Physics 16 (24) (2014) 12194-12201.

[33] Z. Zhao, X. Peng, X. Liu, X. Sun, J. Shi, L. Han, G. Li, J. Luo, Efficient and stable electroreduction of CO 2 to CH 4 on CuS nanosheet arrays, Journal of Materials Chemistry A 5 (38) (2017) 20239-20243.

[34] C. Li, G. Shen, R. Zhang, D. Wu, C. Zou, T. Ling, H. Liu, C. Dong, X.-W. Du, Zn nanosheets coated with a ZnS subnanometer layer for effective and durable CO 2 reduction, Journal of Materials Chemistry A 7 (4) (2019) 1418-1423.

[35] W. Luo, Q. Zhang, J. Zhang, E. Moioli, K. Zhao, A. Züttel, Electrochemical reconstruction of ZnO for selective reduction of CO2 to CO, Applied Catalysis B: Environmental (2020) 119060. 
Author biography

Rees B Rankin Assistant Professor 